\title{
Theories of Learning and Economic Policy
}

\author{
George W. Evans \\ University of Oregon, \\ University of St Andrews
}

March 29, 2021

\begin{abstract}
The benchmark rational expectations (RE) assumption both assumes an unrealistic degree of rationality for economic agents and fails to address how agents would come to coordinate on an equilibrium. This essay reviews how theories of learning, and more specifically adaptive learning, address these issues and can lead to policy conclusions distinct from those obtained under RE. Applications discussed include monetary policy in New Keynesian models, the neoFisherian policy view, inflation targets, hyperinflation models, and macroeconomic policy to avoid stagnation at the zero lower bound.

JEL classification: E62, E63, E52, D84, D83, E31, E32, E71

Key Words: Learning; bounded rationality; expectational coordination, stability; monetary policy; fiscal policy.
\end{abstract}

\section{Introduction}

Expectations of current and future economic variables play a key role in macroeconomic models. Under the benchmark rational expectations (RE) assumption, macromodels can typically be summarized by a dynamic system taking a form like

$$
x_{t}=E_{t} Q\left(x_{t-1}, x_{t+1}\right),
$$

where $x_{t}$ is a vector of variables at time $t$, which may include stochastic exogenous variables as well as endogenous variables, and $E_{t}$ denotes the true 
time $t$ conditional expectation. Often, linearized models are studied, as discussed below. Solving the model under the RE assumption yields a rational expectations equilibrium (REE).

The presence of expectations, and the assumption that economic agents can solve dynamic programing problems, makes macroeconomics inherently different from natural science. Our primary focus here will be on the role of expectations. The learning literature questions the wisdom and plausibility of the RE assumption.

The initial key insight of the "learning" approach to expectation formation is that an REE is an equilibrium in the Nash sense. Having RE is in general rational only if other agents have these expectations: the model is self-referential in the sense that the actual evolution of $y_{t}$ over time depends on the way agents form expectations. This insight of the learning approach leads to its second key insight, which is the need for stability analysis. It is only plausible that agents will coordinate on an REE if there are there are pressures that push agents toward RE if initially expectations deviate from RE. An implied third insight is that in RE models with multiple equilibria, learning can be used as a selection criterion since in many cases only a subset of REE will be locally stable under learning. ${ }^{1}$

Under the learning approach we need to make a decision about how precisely to model rationality at the agent level. My general viewpoint is to follow the "cognitive consistency principle," that we should model agents as about as smart as professional economists. For certain relatively simple economic settings, in which the economic structure is common knowledge, this suggests modeling economic agents like economic theorists, leading to what is called the eductive approach. This is the approach stressed by Roger Guesnerie in a series of papers beginning with Guesnerie (1992). ${ }^{2}$

This research shows that even hyper-rational agents, with complete knowledge of the true structure and full common knowledge of the hyper-rationality of all other agents, may or may not be able to coordinate on RE, depending on whether the structure of the model satisfies non-trivial eductive stability conditions. Thus even hyper-rational agents may be unable to coordinate on an REE.

\footnotetext{
${ }^{1}$ See, for example, Evans (1985), Evans (1989), Evans and Honkapohja (1994a) and Evans and Honkapohja (1995).

${ }^{2}$ See also Guesnerie (2002), Guesnerie (2005), and Evans and Guesnerie (1993). A related line of thought, involving k-level thinking, is consistent with bounded rationality; see Nagel (1995).
} 
In many realistic macroeconomic settings, the cognitive consistency principle instead indicates bounded rationality as the appropriate assumption. After all, we economists do not agree on what is the true model of the macroeconomy, nor do we know the values of model parameters. We also are aware that in our own life-decisions we do not formally solve lifetime optimization problems, based on knowledge of the true transition equations for all variables. Furthermore, we understand that other agents are in the same position and are making boundedly rational forecasts and decisions.

In this essay I will focus on the boundedly-rational adaptive learning approach in which we replace $\mathrm{RE}$ with the more specific assumption that economic agents forecast key aggregate variables using econometric forecast rules with parameters that are updated over time. ${ }^{3}$ The stability issue then is simply whether under adaptive learning the forecast rules converge to an RE forecasting rule as the parameters are updated over time. ${ }^{4}$ This is possible provided the forecast rule specification nests the REE under examination. ${ }^{5}$ The stability conditions for this are typically straightforward to compute, using the E-stability principle: see Evans and Honkapohja (2001). If the econometric forecast rule does not nest an REE there may still be convergence to a "restricted perceptions equilibrium" consistent with the class of forecast rules employed by agents.

This "benchmark" formulation of adaptive learning is consistent with the cognitive consistency principle in the sense that economists, when making forecasts, use econometric procedures with estimated forecast rules that are updated over time. Of course, agents may be less sophisticated, using simple rules of thumb to make forecasts, as is often assumed in "behavioral" approaches to economics. These approaches still fit with the adaptive learning perspective provided agents are choosing between rules based on their relative performance over time. See, for example, Hommes (2013) and also Branch and Evans (2006a) and Branch and Evans (2007).

The adaptive learning approach has implications for economic policy-

\footnotetext{
${ }^{3}$ The adaptive learning approach extends naturally to incorporating boundedly-optimal decision-making. See Branch, Evans, and McGough (2013), Honkapohja, Mitra, and Evans (2013) and Evans and McGough (2018c).

${ }^{4}$ Surveys of this literature that include a wide range of theoretical and policy issues include Evans and Honkapohja (1999), Evans and Honkapohja (2003a) and Evans and Honkapohja (2009), Woodford (2013) and Eusepi and Preston (2018).

${ }^{5}$ Stability conditions under eductive and adaptive learning are distinct but closely related. See Evans and Guesnerie (1993) and Evans, Guesnerie, and McGough (2019).
} 
making and assessing alternative policies that take several distinct forms:

1. Unstable policies. Monetary policy rules need to be evaluated for whether they give solutions that are stable under learning. Even some rules designed to be optimal can have implementations that are unstable under learning.

2. Indeterminate steady states. In forward-looking macro models, some policies may lead to an indeterminate steady state with multiple REE. Generally these include stationary "sunspot solutions," i.e. solutions depending on extraneous exogenous random variables, which may be inefficient yet stable under learning. In other cases both the steady state and the stationary sunspot solutions are unstable under learning, leading to paths that push away from the steady state.

3. Robustness of policies to learning dynamics. Transitional learning dynamics can be important, and under "constant-gain" learning (discussed below) there are persistent (or "perpetual") learning dynamics. The choice of policy parameters should take into account economic performance under perpetual learning.

4. Multiple steady states. In some nonlinear macro models, multiple steady states can arise. The different steady states, which in some cases are Pareto ranked, can be assessed for stability under learning. Monetary and fiscal policies should be designed so that under learning they ensure or make more likely convergence to a preferred steady state.

With these general principles in mind we consider the implications of learning for macroeconomic policy in a range of applications. Before doing so, the next section develops a simple example to provide a basic introduction to the required techniques.

\section{Simple example of adaptive learning}

As discussed below in Section 3, macroeconomic models ideally begin with agent-level decision-making, allowing for possible heterogeneity across agents, and explicitly impose aggregation and market clearing. However, many key issues for policy can be studied in representative-agent models after these steps have already been imposed in a linearized model, yielding a linear reduced form like (1), but in which $E_{t}$ has been replaced by $E_{t}^{*}$, the time $t$ subjective expectations held by agents. Consequently, adaptive learning 
techniques often focus on the following linear set-up,

$$
y_{t}=M E_{t}^{*} y_{t+1}+N y_{t-1}+P w_{t},
$$

where $y_{t}$ is a vector of endogenous variables, $w_{t}$ is a vector of observed exogenous variables and expectations $E_{t}^{*} y_{t+1}$ are formed using an econometric forecasting model, with coefficients updated over time. These forecasting models are often called the "Perceived Law of Motion" (PLM).

As an example, consider a forward-looking univariate linear model

$$
\begin{aligned}
y_{t} & =\beta E_{t}^{*} y_{t+1}+d_{t} \\
d_{t} & =\mu+\rho\left(d_{t-1}-\mu\right)+\varepsilon_{t},
\end{aligned}
$$

where $0<\beta<1,0 \leq \rho<1$ and $\varepsilon_{t}$ is exogenous $i i d\left(0, \sigma_{\varepsilon}^{2}\right)$. This could, for example, represent a risk-neutral asset-pricing model, with exogenous observed stationary $\operatorname{AR}(1)$ dividend process $d_{t}$, where $y_{t}$ is the price of the asset and $E_{t}^{*} y_{t+1}$ is the one one-step-ahead forecast of $y_{t+1} \cdot{ }^{6}$ It is easily verified that under $\mathrm{RE}$ the unique non-explosive solution is

$$
y_{t}=\bar{c}_{0}+\bar{c}_{1} d_{t} \text {, where } \bar{c}_{1}=(1-\beta \rho)^{-1} \text { and } \bar{c}_{0}=(1-\beta)^{-1}(1-\rho) \beta \mu \bar{c}_{1} \text {. }
$$

This REE can also be written as

$$
y_{t+1}=\bar{a}+\bar{b} d_{t}+\tilde{\varepsilon}_{t+1}
$$

where $\tilde{\varepsilon}_{t+1}=(1-\beta \rho)^{-1} \varepsilon_{t+1}$ and

$$
\bar{a}=\frac{\mu(1-\rho)}{(1-\beta)(1-\beta \rho)} \text { and } \bar{b}=\frac{\rho}{1-\beta \rho} .
$$

Under adaptive learning we assume that agents do not know $(\bar{a}, \bar{b})$. However, they have a PLM forecasting model

$$
y_{t+1}=a+b d_{t}+\tilde{\varepsilon}_{t+1},
$$

which nests the REE, and we assume that they use observed data to estimate to estimate the parameters $(a, b)$ and make forecasts based on these estimates. Thus, at the end of time $t-1$, using observed past data $\left\{y_{s}, d_{s-1}\right\}_{s=1}^{t-1}$, the

\footnotetext{
${ }^{6}$ For an application to foreign exchange rates see Chakraborty and Evans (2008).
} 
PLM (5) is estimated by least squares (LS) giving coefficients $\left(a_{t-1}, b_{t-1}\right)$. Using these estimates and the observed dividend $d_{t}$, expectations are

$$
E_{t}^{*} y_{t+1}=a_{t-1}+b_{t-1} d_{t}
$$

The "temporary equilibrium" 7 price of the asset $y_{t}$ is then given by $y_{t}=$ $\beta E_{t}^{*} y_{t+1}+d_{t}$. At the end of $t$ the next data point $\left(y_{t}, d_{t-1}\right)$ is added to the data set and using LS estimates are updated to $\left(a_{t}, b_{t}\right)$, which are used in $t+1$ for forecasting $y_{t+2} \cdot{ }^{8}$

This recursive procedure defines a temporary equilibrium path for dividends and prices. It can be shown that $\left(a_{t}, b_{t}\right) \rightarrow(\bar{a}, \bar{b})$ with probability 1 as $t \rightarrow \infty$. Thus, in this example, adaptive LS learning converges asymptotically to the unique REE. This example can be used to illustrate the E-stability principle. E-stability is defined in term of the map from PLM to the actual law of motion (ALM). For the PLM (5), for any given $(a, b)$ we have forecasts $E_{t}^{*} y_{t+1}=a+b d_{t}$, which, when inserted into (3) gives $y_{t}=\beta a+(\beta b+1) d_{t}$. This implies ALM $y_{t}=\beta a+(\beta b+1) d_{t}$ or

$$
y_{t}=(\beta b+1)(1-\rho) \mu+\beta a+(\beta b+1) \rho d_{t-1}+(\beta b+1) \varepsilon_{t}
$$

which implies $E_{t}^{*} y_{t+1}=T_{a}(a, b)+T_{b}(a, b) d_{t}$ where

$$
T(a, b) \equiv\left(T_{a}(a, b), T_{b}(a, b)\right)=((\beta b+1)(1-\rho) \mu+\beta a,(\beta b+1) \rho) .
$$

Equation (6) gives the mapping from perceived forecast parameters $(a, b)$ to the implied actual forecast parameters. The REE corresponds to a fixed point of this map and E-stability is defined as local asymptotic stability of this fixed point under the notional time ordinary differential equation

$$
\frac{d}{d \tau}(a(\tau), b(\tau))=T(a(\tau), b(\tau))-(a(\tau), b(\tau))
$$

E-stability holds when the eigenvalues of the Jacobian matrix $D T(\bar{a}, \bar{b})$ have real parts less than one. Since here the eigenvalues are $\beta$ and $\beta \rho$ the REE

\footnotetext{
${ }^{7}$ The "temporary equilibrium" terminology was utilized by Hicks (1939).

${ }^{8} \mathrm{~A}$ recursive set-up is enabled by using recursive least-square updating, and the resulting system can be analyzed using stochastic approximation techniques based on an associated differential equation. See Marcet and Sargent (1989) and Evans and Honkapohja (2001). The expectational stability principle is in turn closely related to the associated differential equation for the system.
} 
is E-stable. The E-stability principle states that E-stability governs stability under LS learning, and in the current case this result can be formally proved using stochastic approximation theorems.

For the general multivariate linear model (2), determinacy and E-stability conditions for REE are given in Ch. 10 of Evans and Honkapohja (2001). Important extensions of these results are given in McCallum (2007) and Bullard and Eusepi (2014).

A final apparently technical but practically important issue that needs to be emphasized concerns learning "gains." LS learning is most conveniently formulated using "recursive least-squares" equations ${ }^{9}$ in which coefficients are updated using the most recent forecast error, with the size of adjustment depending on the "gain sequence." The recursive formulation of LS uses a gain sequence $1 / t$. This is called a "decreasing gain" sequence, which arises because LS gives equal weight to each of the observations $1, \ldots, t$. Decreasing gain allows full asymptotic convergence to an REE. ${ }^{10}$

An alternative often used in practice, particularly in empirical models, is to replace $1 / t$ by a (typically small) "constant gain" $0<\gamma<1$. Conceptually this corresponds to discounted LS, with past data discounted at geometric rate $1-\gamma$. Constant gains allow agents to track more quickly structural shifts or policy changes. However this generally implies less than full convergence to REE because estimates remain noisy asymptotically. For example, in the simple risk-neutral asset-pricing model (3), simulations show that under constant-gain LS learning the volatility of asset prices $\operatorname{var}\left(y_{t}\right)$ can be substantially larger than under RE. The extent of excess volatility depends positively both on the size of the gain and on how close $\beta$ is to 1 .

\section{$3 \quad$ Methodological Issues}

As noted in the previous Section, models of the form (2) are typically obtained from linearizations of models in which households and firms have solved their optimization problems, and in which the representative-agent assumption, market-clearing and $\mathrm{RE}$ are imposed, but in which $\mathrm{RE}$ is then replaced by expectations $E_{t}^{*} y_{t+1}$ formed using a statistical forecasting rule with parameters updated over time in accordance with adaptive learning.

\footnotetext{
${ }^{9}$ See e.g. Ch. 2 of Evans and Honkapohja (2001).

${ }^{10}$ For convergence results under both decreasing and constant gains, see Evans and Honkapohja (1998) and Evans and Honkapohja (2001).
} 
Evans and McGough (2020a) and Evans and McGough (2021) call this a "reduced form" approach to adaptive learning.

In models like the Muth (1961) cobweb model, or in two-period overlapping generations models, in which the agent optimization problem is simple, the reduced form learning approach is clearly justifiable. However, most standard macro models, like the real business cycle (RBC) and New Keynesian (NK) models, require agents to solve infinite-horizon dynamic stochastic optimization problems.

In these settings Evans and McGough (2021) argue that an "agent-level" approach should ideally be used, in which one first specifies how agents make decisions based on boundedly optimal solutions to their optimization problems, given their expectations. Agents' conditional supply and demand curves are then aggregated to obtain the period's temporary equilibrium. Under learning agents then update their forecast rules, and, moving to the next period, new exogenous shocks are realized, expectations are formed, and a new temporary equilibrium is realized. The path of the economy under adaptive learning is defined recursively.

An agent-level approach can be implemented in detail in several distinct ways. A central issue is how agents aim to make optimal decisions in infinite or long-horizon settings. Evans and Honkapohja (2006) and Honkapohja, Mitra, and Evans (2013) show that if agents make decisions based on onestep ahead Euler equations, this approach is compatible with reduced-form learning. The long-horizon approach of Preston (2005) and emphasized, for example, in Eusepi and Preston (2018), assumes agents at each point in time make decisions that are optimal, given their expectations of the entire future path of variables exogenous to their control (while neglecting that these expectations will be updated over time).

Adam, Marcet, and Nicolini (2016) assume that agents are internally rational, in the sense that they behave as Bayesian decision-makers who fully optimize, given their subjective probability distribution over variables outside their control, even though these subjective distributions may be inconsistent with the true distributions, and thus not externally rational.

Evans and McGough (2018c) show that Euler-equation learning can be viewed as a special case of shadow-price learning. They show that shadowprice learning is boundedly optimal: it leads asymptotically to fully optimal decision making in linear-quadratic settings. Shadow-price learning can be implemented in general nonlinear environments, as well as when there are heterogeneous agents. 
These different agent-level approaches have different advantages. Evans and McGough (2021) examines the relative performance of Euler-equation, shadow-price and long-horizon decision-making within a standard RBC setting in which the economy experiences a change in fiscal policy. Although there are numerous detailed differences, one message from this application is that qualitatively the outcomes of different agent-level implementations of bounded rationality share many common features. Reduced-form learning, in this and other examples, appears to provide a satisfactory short-cut to results on asymptotic stability and transition dynamics, which align with agent-level implementations of adaptive learning.

\section{Monetary Policy}

The implications of learning for monetary policy are extensive. We focus on several key issues. To keep the discussion compact, the presentation focuses on reduced-form adaptive learning.

\subsection{Policy rules in the canonical NK model}

Consider the canonical linearized New Keynesian (NK) model

$$
\begin{aligned}
& x_{t}=-\varphi\left(i_{t}-E_{t}^{*} \pi_{t+1}\right)+E_{t}^{*} x_{t+1}+g_{t} \\
& \pi_{t}=\beta E_{t}^{*} \pi_{t+1}+\lambda x_{t}+u_{t},
\end{aligned}
$$

where $0<\beta<1$ is the discount factor and $\varphi, \lambda>0$. Here $x_{t}$ is the output gap, $\pi_{t}$ is inflation and $i_{t}$ is the nominal interest rate, all of which are expressed as deviations from their steady-state values. ${ }^{11}$ These are called the NK IS and NK PC equations. The exogenous shocks $g_{t}, u_{t}$ are assumed to be observable independent, stationary, mean zero $\operatorname{AR}(1)$ processes:

$$
g_{t}=\mu g_{t-1}+\varepsilon_{g t} \text { and } u_{t}=\rho u_{t-1}+\varepsilon_{u t} \text {, where } 0<\mu, \rho<1 \text {, }
$$

and $\varepsilon_{g t}, \varepsilon_{u t}$ are iid mean zero. We consider a forward-looking Taylor-type interest-rate rule given by

$$
i_{t}=\chi_{\pi} E_{t}^{*} \pi_{t+1}+\chi_{x} E_{t}^{*} x_{t+1},
$$

\footnotetext{
${ }^{11}$ The (steady state) target inflation rate for monetary policy needs to be close to zero for this formulation to be a suitable approximation.
} 
where $\chi_{\pi}, \chi_{x}>0$. John Taylor recommended $i_{t}$ respond more than one-forone to inflation - the "Taylor principle"; for (9) this would mean $\chi_{\pi}>1$. Substituting out $i_{t}$ the model can be written as a bivariate forward-looking model

$$
y_{t}=M E_{t}^{*} y_{t+1}+P v_{t}
$$

where $y_{t}^{\prime}=\left(x_{t}, \pi_{t}\right)$ and $v_{t}^{\prime}=\left(g_{t}, u_{t}\right)$, and $M$ and $P$ are $2 \times 2$ matrices. ${ }^{12}$

The form of the "reduced-form" model (10) is a bivariate extension of the model (3), with the exception that in (10) we have suppressed the intercepts by expressing variables in deviation from mean form. When assessing stability under learning we include intercepts because agents need to learn the means of the variables they are forecasting. The model (10) is determinate, i.e. has a unique nonexplosive REE, when both roots of $M$ lie inside the unit circle, and in this case the REE takes the form $y_{t}=\bar{b} v_{t}$, where $\bar{b}$ is a $2 \times 2$ matrix depending on the parameters.

Bullard and Mitra (2002) investigated this model for determinacy and stability under adaptive learning, for the policy rule (9) as well as for contemporaneous and backward-looking Taylor rules. Additional results, concerning stability of sunspot equilibria in the indeterminate case, were obtained by Honkapohja and Mitra (2004), Evans and McGough (2005) and, within a nonlinear setting, Evans and McGough (2020b). For the policy rule (9), two main results are that if $\chi_{\pi}>1$ and $\chi_{x}$ is not too large then the model is determinate and the REE is stable under learning. However, for $\chi_{\pi}>1$ if $\chi_{x}$ is too large the model is indeterminate with sunspot solutions that are stable under adaptive learning. ${ }^{13}$ Thus forward-looking rules with $\chi_{\pi}>1$ should not respond too aggressively to expected future output gaps.

Optimal policy has also been studied in this set-up, see e.g. Clarida, Gali, and Gertler (1999) and Woodford (1999). Suppose the objective function of the policymaker can be approximated by $E_{t} \sum_{s=0}^{\infty} \beta^{s}\left(\pi_{t+s}^{2}+\alpha x_{t+s}^{2}\right)$. Under "optimal discretionary" policy the first-order condition (FOC) for optimal policy is $\lambda \pi_{t}+\alpha x_{t}=0$. Under commitment the policymaker can do better, as a result of the effect on private sector expectations, and the corresponding FOC, for commitment under the "timeless perspective," is

\footnotetext{
${ }^{12}$ Under long-horizon adaptive learning, the assumption that agents know the form of the interest rate rule is non-trivial, and an important issue. See Eusepi and Preston (2010).

${ }^{13}$ The possibility of REE sunspot equilibria was originally investigated by Shell (1977), Azariadis (1981), Azariadis and Guesnerie (1982), Cass and Shell (1983) and Azariadis and Guesnerie (1986). Early papers examining stability under learning of sunspot equilibria include Woodford (1990), Evans (1989) and Evans and Honkapohja (1994b).
} 
$\lambda \pi_{t}+\alpha\left(x_{t}-x_{t-1}\right)=0$. A full specification of monetary policy requires provision of an interest-rate rule (or "reaction function") that implements the policy, consistent with the FOC.

For simplicity consider implementation of optimal discretionary policy. An apparently natural choice - a "fundamentals-based rule" - can be obtained as follows. Using the FOC $\lambda \pi_{t}+\alpha x_{t}=0$ in (8) to eliminate $x_{t}$, and imposing RE, gives a univariate forward-looking system in $\pi_{t}$ driven by $u_{t}$. This can be solved to obtain the optimal REE $\pi_{t}=\bar{d}_{1} u_{t}$, where $\bar{d}_{1}$ depends on $\beta, \rho, \lambda$ and $\alpha$, and $x_{t}=-\alpha^{-1} \lambda \bar{d}_{1} u_{t}$. Substituting this solution into (7) and imposing RE it then follows that the interest rate satisfies

$$
i_{t}=\psi_{u} u_{t}+\psi_{g} g_{t}
$$

where $\psi_{u}, \psi_{g}$ are functions of the parameters. For algebraic details see Evans and Honkapohja (2003b). When viewed as a policy rule to implement optimal monetary policy we call (11) the "fundamentals-based" interest-rate rule.

However, consider the system given by (7), (8) and the policy rule (11). Under adaptive learning agents have forecast rules

$$
\left(\begin{array}{c}
E_{t}^{*} \pi_{t+1} \\
E_{t}^{*} x_{t+1}
\end{array}\right)=a+b u_{t}
$$

where $a$ is $2 \times 1$ and $b$ is $2 \times 2$. The time $t$ estimates $a_{t}, b_{t}$ are updated over time using LS to regress $\pi_{t+1}$ and $x_{t+1}$ on an intercept and $u_{t} \cdot{ }^{14}$ It is straightforward to show that the optimal REE is not E-stable and hence not stable under learning. Thus the apparently optimal policy rule (11) is fundamentally defective from the learning viewpoint. ${ }^{15}$

The key to implementing optimal policy so that it is stable under adaptive learning is to not assume agents have RE. To get an appropriate interest rate rule, combine equations (7) and (8) with the FOC $\lambda \pi_{t}+\alpha x_{t}=0$, while taking subjective expectations $E_{t}^{*} \pi_{t+1}, E_{t}^{*} x_{t+1}$ as given. Eliminating $\pi_{t}$ and $x_{t}$ from the system gives an interest-rate rule of the form

$$
i_{t}=\delta_{\pi} E_{t}^{*} \pi_{t+1}+\delta_{x} E_{t}^{*} x_{t+1}+\delta_{g} g_{t}+\delta_{u} u_{t},
$$

where the coefficients depend on the underlying parameters. This is a Taylortype rule, viewed now as responding to private-sector expectations, but augmented by a dependence on the observed exogenous shocks. It can be shown

\footnotetext{
${ }^{14}$ Agents could also include $g_{t}$ as a regressor. This does not affect the results.

${ }^{15}$ The system is also indeterminate under the fundamentals-based rule.
} 
that this "expectations-based" rule is stable under LS learning: agents will learn over time to have RE and the economy will converge to optimal discretionary policy. Again, see Evans and Honkapohja (2003b) for details.

These results carry over to the case in which policymakers can commit to optimal policy satisfying the timeless perspective: the corresponding fundamentals-based rule is unstable under learning, while the analogous expectations-based rule is stable under learning. See Evans and Honkapohja (2006).

\subsection{Neo-Fisherian policy}

Following the Financial Crisis of 2008-9, the US federal funds rate was essentially at the zero lower bound (ZLB) for the whole period $2009-2015$. Beginning Dec. 2015 the Fed started to normalize interest rates. This can be viewed as a return to a Taylor rule. The Neo-Fisherian view- see Cochrane (2011), Cochrane (2016), Williamson (2016b), Williamson (2016a) - is that normalization should instead be to a fixed interest rate peg at the steady state level consistent with the $2 \%$ inflation target. Based on adaptive learning, Evans and McGough (2018b) and Evans and McGough (2018a) argue that the neo-Fisherian view is misguided.

Neo-Fisherianism starts from the Fisher equation

$$
i=r+\pi
$$

where $i$ is the net nominal interest rate, $r$ is the corresponding real interest rate and $\pi$ is the inflation rate. In steady state $r$ is determined by $\beta$ and the growth rate. The neo-Fisherian argument is simple: given $r$, if the inflation target is $\bar{\pi}$ then $i$ should be set at $\bar{\imath} \equiv r+\bar{\pi}$. In the basic NK model, and for simplicity ignoring exogenous shocks, the steady state is an REE and it must satisfy $E_{t}^{*} \pi_{t+1}=\pi=\bar{\imath}-r=\bar{\pi}$.

The neo-Fisherian policy conclusion is that if interest rates are low and inflation and expected inflation are below target, policymakers should set a fixed interest rate peg at the higher level $\bar{\imath}=r+\bar{\pi}$. The Fisher equation then, according to this view, ensures that $\pi, E_{t}^{*} \pi_{t+1}$ increase in line with $\bar{\imath}$. The neo-Fisherian argument goes against conventional wisdom that lower $i$ increases $\pi$ by increasing demand. Evans and McGough (2018b) argue that the conventional view is right, and that neo-Fisherian policies are prone to instability and recession. 
How does the Evans-McGough critique of the neo-Fisherian policy view differ from the view based simply on an RE perspective? It is well-known that a fixed interest-rate peg can lead to indeterminacy, i.e. to multiple REE, and from a purely RE perspective the implications of indeterminacy are unclear. One cannot rule out the RE solutions a priori, and in the current case there is a continuum of solutions that are well-behaved and converge to the steady state. Indeed, Cochrane (2016) and Williamson (2016a) recognize this indeterminacy, and focus on the RE result that, following an increase in the interest rate peg, all of these $\mathrm{RE}$ paths converge to the higher inflation steady state.

The adaptive learning perspective is that multiplicity begs an assessment of stability, and stability results are in general model dependent. For example, in some models with an indeterminate steady state, both the steady state and sunspot solutions in a neighborhood of the steady state are stable under learning, while in other cases these solutions are not stable under learning. Similarly in models with multiple RE steady states, one or more RE steady states may be stable under learning while other steady states are not. In the current case an analysis of stability under learning is therefore required.

Evans and McGough (2018b) investigate this in detail using the longhorizon New Keynesian models developed in Eusepi and Preston (2010) and employed in Evans, Honkapohja, and Mitra (2016). However, Evans and McGough (2018b) also illustrate their arguments using a simple short-horizon model introduced by Kocherlakota (2016) and used by Williamson (2016a) in discussing an earlier version of Evans and McGough (2018b).

This simplified NK model may be written

$$
\begin{aligned}
x_{t} & =-\sigma^{-1}\left(i_{t}-E_{t}^{*} \pi_{t+1}-r\right)+E_{t}^{*} x_{t+1} \\
\pi_{t} & =\xi x_{t}+u_{t} \\
i_{t} & =\bar{\imath}+\chi_{\pi} E_{t}^{*}\left(\pi_{t+1}-\bar{\pi}\right),
\end{aligned}
$$

where $\sigma, \xi \geq 0$. Here $x$ is the output gap, $\pi$ is the net inflation rate (now not in deviation from mean form), $\bar{\pi}$ is the inflation target, which we now make explicit, $i$ is the net nominal interest rate, and $\bar{\imath}=r+\bar{\pi}$ is the interest-rate target. Equation (12) is the IS-relation. Equation (13) is a non-accelerationist Phillips curve with slope $\xi>0$; this curve can be viewed as an NK Phillips curve with the usual dependence on $E_{t}^{*} \pi_{t+1}$ eliminated, and $u_{t}$ is a white noise inflation shock. Equation (14) is the policy rule: $\chi_{\pi}=0$ corresponds to an interest-rate peg and $\chi_{\pi}>1$ satisfies the Taylor principle. The interest- 
rate and inflation targets are assumed compatible with a long-run steady state: $\bar{\pi}=\bar{\imath}-r$. The non-stochastic steady state of this model (for $u_{t} \equiv 0$ ) is given by $x_{t}=\bar{x}=\xi^{-1} \bar{\pi}, i_{t}=\bar{\imath}$, and $\pi_{t}=\bar{\pi}$.

The simplified model (12)-(14) has, as an REE, the stochastic steady state $x_{t}=\bar{x}$ and $\pi_{t}=\bar{\pi}+u_{t}$, so that $E_{t} \pi_{t+1}=\bar{\pi}$. The model can be reduced to a univariate framework by assuming agents understand (13), so that

$$
E_{t}^{*} x_{t+1}=\xi^{-1} E_{t}^{*} \pi_{t+1} \text {. }
$$

Combining equations we get the temporary equilibrium model

$$
\pi_{t}=(1-\psi) \bar{\pi}+\psi E_{t}^{*} \pi_{t+1}+v_{t}, \text { where } \psi=1-\sigma^{-1} \xi\left(\chi_{\pi}-1\right) .
$$

Under adaptive learning we assume agents do not fully trust the inflation target $\bar{\pi}$ because they have doubts about either the central bank's commitment and/or its ability to hit the target. Thus private agents update their inflation forecasts using observed data according to the rule

$$
E_{t}^{*} \pi_{t+1}=a_{t}, \text { where } a_{t}=a_{t-1}+t^{-1}\left(\pi_{t-1}-a_{t-1}\right),
$$

where we here focus on the decreasing gain case.

Our set-up under adaptive learning is a special case of Section 2, and the E-stability principle immediately gives the key result. Because the shock is white noise the forecast PLM is just $E_{t}^{*} \pi_{t+1}=a$. The corresponding ALM is $\pi_{t}=(1-\psi) \bar{\pi}+\psi a+v_{t}$ with associated forecasts $E_{t}^{*} \pi_{t+1}=T(a)=$ $(1-\psi) \bar{\pi}+\psi a$. E-stability thus holds when $\psi<1$ and fails when $\psi>1$. An interest-rate peg corresponds to $\chi_{\pi}=0$ and $\psi>1$, and thus fails to be E-stable, whereas E-stability holds if $\chi_{\pi}>1$ since then $\psi<1$. These results extend to the case in which $u_{t}$ is a stationary $\operatorname{AR}(1)$ process.

It follows that the REE steady state is stable under adaptive learning when $\chi_{\pi}>1$ but not when $\chi_{\pi}=0$ : inflation does not converge to the policy target under an interest-rate peg. ${ }^{16}$ Instead an interest-rate peg generates trajectories that push away from the steady state.

Further results confirming the instability under learning of interest-rate pegs are provided in Evans and McGough (2018b), including results for longhorizon NK models; the paper also discusses the policy implications for normalizing interest rates in the wake of the Great Recession. In particular they

\footnotetext{
${ }^{16}$ Under an interest-rate peg there are also stationary sunspot equilibria. These solutions are also unstable under learning.
} 
find that, when inflation expectations are below the target inflation rate, implementation of an interest-rate peg at a higher rate is likely to lead to generate explosive trajectories pushing away from steady state, with decreasing output and inflation.

The instability result for fixed interest-rate pegs in the basic NK model of Section 4.1 was already implied by the results of Bullard and Mitra (2002). Indeed the problems with fixed interest rate pegs in macromodels had earlier been analyzed by Howitt (1992).

\subsection{Unstable Inflation targets}

The ZLB to interest rates was a binding constraint in the US and other countries following 2007. One policy response suggested for relaxing this constraint is to raise the inflation target $\bar{\pi}$. The higher nominal interest rate target $\bar{l}=\bar{\pi}+r$ would provide more room for reductions in $i$ when there are large adverse demand shocks. A caution to this based on adaptive learning considerations arises from the possibility of persistent learning dynamics. Branch and Evans (2017) make the point that increases in the inflation target can lead to temporarily self-fulfilling but unstable learning dynamics.

The essence of the argument can be given in a simple univariate model. Consider a flexible-price representative-agent economy with money in the utility function and a fixed per-period endowment of perishable goods. When log-linearized around the steady state the system can be reduced to two equations: the Fisher equation $\hat{\imath}_{t}=E_{t}^{*}\left(\pi_{t+1}-\bar{\pi}\right)+r_{t}$, where $\hat{\imath}_{t}$ is the deviation of the interest rate from its steady-state value and $r_{t}$ is a white-noise shock to the real interest rate; and a contemporaneous Taylor-interest-rate rule, $\hat{\imath}_{t}=\alpha\left(\pi_{t}-\bar{\pi}\right)$, where $\alpha>1{ }^{17}$ Combining equations gives

$$
\pi_{t}=\alpha^{-1}(\alpha-1) \bar{\pi}+\alpha^{-1} E_{t}^{*} \pi_{t+1}+\alpha^{-1} r_{t} .
$$

This equation is a special case of the Section 2 model. There is a unique nonexplosive REE that takes the form $\pi_{t}=\bar{\pi}+\alpha^{-1} r_{t}$, and this solution is stable under learning since $\alpha>1$. Suppose, however, that agents overparameterize this solution by allowing for AR(1) dynamics,

$$
\pi_{t}=a+b \pi_{t-1}+\varepsilon_{t} .
$$

\footnotetext{
${ }^{17}$ See Evans and McGough (2018a) for further details of the underlying temporary equilibrium system in a closely related set-up.
} 
Thus agents allow for the possibility that inflation is serially correlated. ${ }^{18}$ In the REE $b=0$ and the solution $(a, b)=(\bar{\pi}, 0)$ is E-stable and thus stable under learning. However, Branch and Evans (2017) show that when constantgain LS learning is used, there are "escape dynamics" of the type documented in various settings by Sargent (1999), Cho, Williams, and Sargent (2002), McGough (2006), Kasa (2004) and Branch and Evans (2011). ${ }^{19}$.

Stochastic simulations find that occasionally paths arise in which $\left(a_{t}, b_{t}\right)$ converge, for a sustained period of time, to near $(0,1)$, a random-walk forecast, during which time $\pi_{t}$ is volatile, before eventually $\left(a_{t}, b_{t}\right)$ returns to near the $\operatorname{REE}(\bar{\pi}, 0)$. The intuition for this is that while $(a, b)=(0,1)$ does not correspond to an equilibrium, it is approximately self-fulfilling. To see this note that under the PLM $(a, b)$ the corresponding forecast, under the assumption that expectations are formed at the start of $t$, is $E_{t}^{*} \pi_{t+1}=a(1+b)+b^{2} \pi_{t-1}$. Inserting this into (17) gives the ALM

$\pi_{t}=\alpha^{-1}(\alpha-1) \bar{\pi}+\alpha^{-1} a(1+b)+\alpha^{-1} b^{2} \pi_{t-1}+\alpha^{-1} r_{t} \equiv T_{a}(a, b)+T_{b}(a, b) \pi_{t-1}+\alpha^{-1} r_{t}$

The REE corresponds to the fixed point of $T(a, b)=\left(T_{a}(a, b)+T_{b}(a, b)\right)$ given by $(a, b)=(\bar{\pi}, 0)$. However if $\alpha>1$ is close to 1 then $(a, b)=(0,1)$ is close to being rational in the sense the forecasts are almost self-fulfilling.

Near random-walk forecasts arise from occasional sequences of random shocks $r_{t}$ that are interpreted under LS learning as a positively serially correlated inflation process. The frequency and likelihood of random-walk beliefs depend on how close $\alpha$ is to one, and it also depends on the level of the inflation target $\bar{\pi}$. An increase in the inflation target results in a sequence of forecast errors that is particularly likely to induce random walk beliefs. Branch and Evans (2011) show that these key insights and similar results arise in sticky-price bivariate New Keynesian models including versions that incorporate trend inflation.

There are clear implications for policy. If a central bank increases its inflation target their commitment to the new target needs to be as credible as possible: if agents constrain their forecasts to impose the new target as the mean, then random walk beliefs will not arise. Alternatively, the policy rule should employ a large reaction coefficient $\alpha$ to prevent drifts in expectations towards random walk beliefs.

\footnotetext{
${ }^{18}$ Indeed there is another REE with $\operatorname{AR}(1)$ parameter $\alpha^{-1}$. This solution is explosive, though with $\alpha>1$ close to 1 , it is only mildly explosive.

${ }^{19}$ See also Evans and Honkapohja (1993a) and Evans and Honkapohja (2001), Ch. 14.
} 


\section{$5 \quad$ Policy in Nonlinear Models}

In nonlinear models of the form (1), multiple steady states can arise, and adaptive learning can play a central role for policy. ${ }^{20}$ We focus on two applications.

\subsection{Hyperinflation}

Monetary models in which government expenditure is partly or wholly financed by money creation can have two steady states. The simplest set-up is an overlapping generations model. For the case in which a real deficit $d_{t}$ is financed by money creation, i.e. $p_{t} d_{t}=h_{t}-h_{t-1}$, and in which the real demand for money $m_{t}=h_{t} / p_{t}$ by young agents is a negative function $m\left(\pi_{t+1}^{e}\right)$, where $\pi_{t+1}=p_{t+1} / p_{t}$ is the inflation factor, the temporary equilibrium equation takes the form $\pi_{t}=m\left(\pi_{t}^{e}\right) /\left(m\left(\pi_{t+1}^{e}\right)-d_{t}\right)$. Here and in Section 5.2 it is convenient to use the notation $\pi_{t+1}^{e} \equiv E_{t}^{*} \pi_{t+1}$ and $\pi_{t}^{e} \equiv E_{t-1}^{*} \pi_{t}$.

If utility of consumption takes an additive log form, then, for suitable endowments of labor time, $m\left(\pi_{t+1}^{e}\right)=a-b \pi_{t+1}^{e}$ for $a, b>0$ provided this is positive. If $d_{t}=d>0$ is not too large there are two perfect foresight steady-state inflation rates $\pi^{A}<\pi^{B}$.

This model has been studied under both RE and adaptive learning. See Sargent and Wallace (1987), Evans and Ramey (1995), Evans, Honkapohja, and Marimon (2001) and Marcet and Nicolini (2003). The RE literature focused on the result that the low-inflation steady state $\pi^{A}$ is determinate while $\pi^{B}$ is indeterminate. There are thus perfect foresight paths $\pi_{t}$, starting from an initial inflation rate $\pi^{A}<\pi_{0}<\pi^{B}$, in which $\pi_{t} \rightarrow \pi^{B}$. These were viewed as hyperinflation paths. However, these perfect foresight hyperinflation paths have an apparently paradoxical policy implication. An increase in the deficit $d$ increases $\pi^{A}$ and decreases $\pi^{B}$. Consequently this suggests that if $\pi_{t}=\pi^{B}$, then inflation can be reduced by increasing the deficit. ${ }^{21}$

Adaptive learning provides the opposite policy conclusion. Under a steadystate learning rule like (16) it can be shown that $\pi^{A}$ is locally stable under learning, while $\pi^{B}$ is locally unstable. This holds also in stochastic versions of the model, in which $d_{t}$ is random with mean $d$. Hyperinflation can still

\footnotetext{
${ }^{20} \mathrm{~A}$ more general set-up that allows for expectations of nonlinear functions of future variables, takes the implicit form $E_{t}^{*} Q\left(y_{t}, y_{t-1}, y_{t+1}, w_{t}\right)=0$, where $E_{t}^{*}$ denotes subjective conditional expectations.

${ }^{21}$ This assumes $d$ is not increased to more than the level at which $\pi^{A}$ and $\pi^{B}$ coalesce.
} 
emerge if a sequence of random shocks happens to drive expectations above $\pi^{B}$, at which point inflation under adaptive learning will tend to explode along an unstable inflationary path that, if unimpeded, would lead to currency collapse. ${ }^{22}$

Evans, Honkapohja, and Marimon (2001) and Marcet and Nicolini (2003) extend the adaptive learning model in two directions. Evans, Honkapohja, and Marimon (2001) assume there is a limit on the ratio $\lambda$ of the deficit $d$ relative to GDP (the portion of goods, produced by the young, entering the market). This ensures there will always exist a steady state that is stable under learning, even if $d$ is large. For $d$ small enough so that $\pi^{A}$ and $\pi^{B}$ exist, and for $\lambda$ large, there are now three steady states $\pi^{A}<\pi^{B}<\pi^{C}$, with $\pi^{A}$ and $\pi^{C}$ locally stable under learning. The comparative statics for policy in this version of the model are now natural at both $\pi^{A}$ and $\pi^{C},{ }^{23}$ and, furthermore, Evans, Honkapohja, and Marimon (2001) provide laboratory evidence in support of the adaptive-learning predictions. ${ }^{24}$

Marcet and Nicolini (2003) place the hyperinflation model, with two steady states $\pi^{A}<\pi^{B}$, within an open economy context. Under normal policy, the foreign exchange rate is flexible and purchasing power parity holds. However, if inflation would otherwise be above some critical level $\pi^{U}>\pi^{B}$ then policymakers switch to an exchange-rate rule regime with the target exchange rate target chosen so that the inflation rate is reduced to $\pi=\pi^{A}$. This stabilizes inflation and expected inflation, at which point the exchange-rate rule regime is lifted. Marcet and Nicolini (2003) show that this set-up can lead to recurring bouts of hyperinflation that fit the stylized facts of South American countries subject to recurring hyperinflation episodes. ${ }^{25}$ The policy implications are again natural, e.g. a reduction in the deficit lowers the frequency of hyperinflation episodes.

\footnotetext{
${ }^{22}$ Such paths under learning also arise if $d$ is so large that no steady state exists. The possibility of currency collapse under bounded rationality was emphasized in Evans and Ramey (1995).

${ }^{23}$ Evans and Honkapohja (2007) show how Paul Samuelson's correspodence principle, linking comparative statics to stability, extends to expectational stability.

${ }^{24}$ In related work Evans, Honkapohja, and Marimon (2007) show, in a cash-in-advance model with government spending partly financed by seigniorage, that, if the intertemporal elasticity of substitution of labor is less than one, there is an indeterminate steady state with sunspot equilibria that are stable under adaptive learning. Fiscal policy can be used to eliminate the sunspot equilibria.

${ }^{25}$ Marcet and Nicolini (2003) use gains that switch endogenously between constant and decreasing gain. This leads to eventual convergence to the low-inflation steady state.
} 
A formally similar structure underlies several papers on stock-price dynamics. In Branch and Evans (2011) there are two distinct self-fulfilling solutions, a fundamentals steady state and a dynamically explosive rational bubble solution. In Adam, Marcet, and Nicolini (2016) the fundamentals steady state is complemented by a singularity that is the analog of an explosive rational bubble. In both papers, under adaptive learning the fundamentals steady state is locally stable, but is prone to unstable trajectories that temporarily go away from the fundamentals steady state.

\subsection{Stagnation and the ZLB}

Multiple steady states arise in New Keynesian models as a result of the ZLB for net interest rates. As emphasized by Benhabib, Schmitt-Grohe, and Uribe (2001), if the interest-rate rule satisfies the Taylor principle at the targeted steady state inflation rate $\pi_{t} \equiv p_{t} / p_{t-1}=\pi^{*}$, then for continuous interestrate rules there will exist another steady state at $\beta^{-1} \leq \pi_{L}<\pi^{*}$. Thus we have two RE steady states, a locally determinate steady state at $\pi^{*}$ and a locally indeterminate steady state at $\pi_{L} \cdot{ }^{26}$

As in the neo-Fisherian set-up, under RE this global indeterminacy raises the question of which solution should be selected. Since there are an infinity of RE paths, indexed by initial expectations, that converge to the $\pi_{L}$ steady state, one possible view is that one of these paths is most likely. An alternative $\mathrm{RE}$ viewpoint is that, faced with global indeterminacy, a determinate steady state, here the $\pi^{*}$ steady state, should be selected. The adaptive learning perspective instead argues that an expectational stability analysis is required: attainable $\mathrm{RE}$ solutions are those that can be reached over time by an adaptive learning process (an "evolutionary process" in the terminology of Sargent (2008))).

The situation under adaptive learning is presented most simply using the NK model based on Rotemberg price-adjustment costs. Evans, Guse, and Honkapohja (2008) show that under Euler-equation learning this leads to a

\footnotetext{
${ }^{26}$ This model also has rational sunspot equilibria.
} 
nonlinear bivariate temporary equilibrium system:

$$
\begin{aligned}
\frac{\alpha \gamma}{\nu}\left(\pi_{t}-1\right) \pi_{t}= & \beta \frac{\alpha \gamma}{\nu}\left(\pi_{t+1}^{e}-1\right) \pi_{t+1}^{e} \\
& +\left(c_{t}+g_{t}\right)^{(1+\varepsilon) / \alpha}-\alpha\left(1-\frac{1}{\nu}\right)\left(c_{t}+g_{t}\right) c_{t}^{-\sigma_{1}} \\
c_{t}= & c_{t+1}^{e}\left(\pi_{t+1}^{e} / \beta R\left(\pi_{t}\right)\right)^{1 / \sigma_{1}}
\end{aligned}
$$

where $c_{t}$ is consumption, $g_{t}$ is government spending and $R(\pi)$ is the interestrate rule. Here $\pi_{t+1}^{e}$ and $c_{t+1}^{e}$ denote $E_{t}^{*} \pi_{t+1}$ and $E_{t}^{*} c_{t+1}$. The first equation is the NK Phillips curve and the second equation is the consumption Euler equation. ${ }^{27}$ Here $\pi_{t+1}^{e}$ and $c_{t+1}^{e}$ denote $E_{t}^{*} \pi_{t+1}$ and $E_{t}^{*} c_{t+1}$

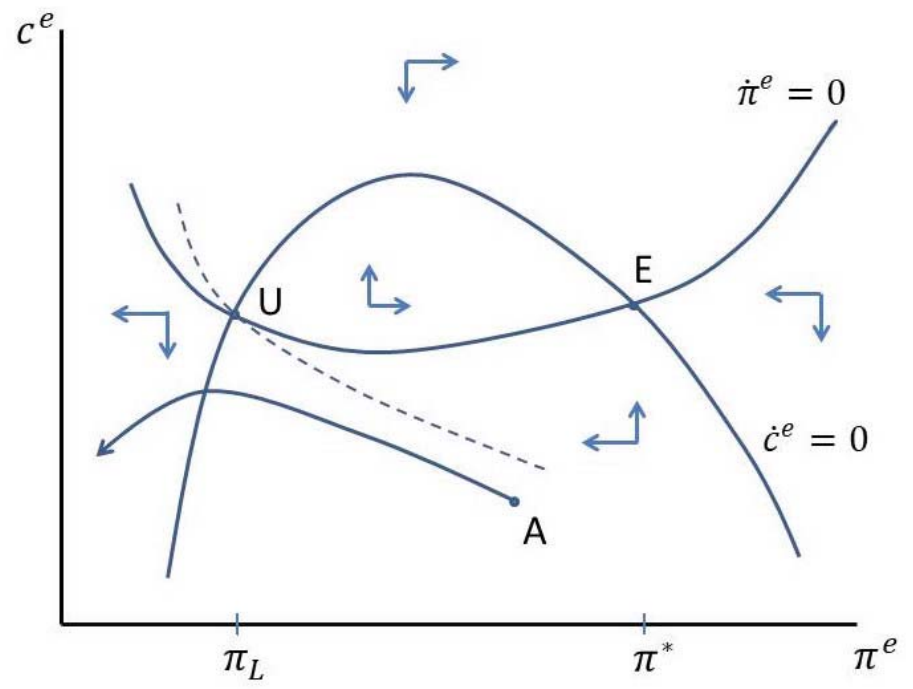

Figure 1: Locally stable targeted steady state E and stagnation path starting from A

Figure 1 shows the situation under adaptive learning. The targeted steady state $\pi^{*}$ at $\mathrm{E}$ is locally stable under learning, whereas the unintended lowinflation steady state $\pi_{L}$ at $\mathrm{U}$ is not locally stable under learning. It is worth noting that the levels of consumption (and output) are about the same at

\footnotetext{
${ }^{27} \mathrm{~A}$ long-horizon version of this model under adaptive learning is developed in Benhabib, Evans, and Honkapohja (2014).
} 
E and U. Based simply on local learning stability results one might simply conclude that equilibrium E should be selected. However, the global stability analysis illustrated in Figure 1 reveals a major issue of concern: the steady state $\mathrm{E}$ is locally but not globally stable under learning.

Suppose initial expectations are pessimistic, to the southwest of the dashed line, e.g. at point A. Under learning dynamics the economy then follows a path with eventually falling output and inflation. This region is called the "stagnation trap" or "deflation trap." Evans, Guse, and Honkapohja (2008) show that if there is a large negative expectations shock, following some event like a financial crisis, that shifts expectations into the stagnation trap, temporary aggressive monetary and fiscal policy can in effect push the economy back into the basin of attraction of the targeted steady state. The role of fiscal policy is further explored in Benhabib, Evans, and Honkapohja (2014), and Evans, Honkapohja, and Mitra (2020).

If unimpeded by aggressive monetary and fiscal policy, what ultimately happens under a trajectory, like the one starting at point $\mathrm{A}$ in Figure 1, in which consumption and inflation fall over time? Evans, Honkapohja, and Mitra (2020) show, in a version of this model in which private and government consumption are partial substitutes, that there is a well-defined RE third steady state with a very low level of output and rapid deflation. This "stagnation" steady state is stable under learning.

Adaptive learning thus both resolves the selection issue and has major policy implications: if expectations are not too far from the targeted steady state E, the economy under adaptive learning, and with unchanged policy, will converge over time to E. If instead expectations are outside the basin of attraction for E, the economy, under unchanged policy, would follow a trajectory that ultimately converges to a stagnation steady state. However, from starting points like A, outside the basin of attraction for E, aggressive fiscal and monetary policy can be used to move the economy to a trajectory that eventually takes it to the targeted steady state E.

The adaptive learning results for this model differ from those under RE in two crucial ways. First, under RE, there is a continuum of paths that converge to $\mathrm{U}$ (as well as stationary sunspot local to $\mathrm{U}$ ). These solutions are not stable under adaptive learning. Learning analysis instead reveals, and emphasizes, the region in which the paths have falling output and inflation. Secondly, while policy under RE also often focuses on expansionary monetary and fiscal policies desirable at the interest-rate zero lower bound, this is usually studied in the context of responding to fundamental discount 
rate or credit-spread shocks (typically assumed to be temporary and to end with a fixed probability each period). The adaptive learning story focuses instead on pessimistic expectations that can still be present after fundamental shocks are gone. Suppose, in the aftermath, say, of a credit crisis, the fundamental credit shocks have ended, but expectations remain pessimistic and are currently at point A. Then, even though the targeted rational steady state is at E, output and inflation will remain low, and learning dynamics will drive the economy further into deep recession, unless these forces are offset by aggressive expansionary macro policies.

\subsection{Other applications}

There are a number of macromodels with three steady states that are Pareto ranked. These can be viewed as models of "coordination failure" because there exist steady states that are locally stable under adaptive learning, but

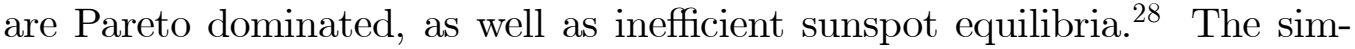
plest models of this type have either positive production externalities or monopolistic competition and increasing returns. The "increasing social returns" model used in Evans and Honkapohja (1993a), Evans and Honkapohja (1993b) and Evans and Honkapohja (2001), Ch. 4.6 and 14.3, introduces a positive production externality into an overlapping generations model with production. For a range of parameters there are three steady states; the high and low output steady states are locally stable under learning, while the middle steady state is unstable under learning. Under adaptive learning, production subsidies can be used to steer the economy away from Pareto dominated steady states and can eliminate sunspot equilibria or endogenous fluctuations arising under learning dynamics.

Other examples of forward-looking models with two locally stable steady states under learning include the labor search model of Howitt and McAfee (1992) and the endogenous growth model of Evans, Honkapohja, and Romer (1998). In the latter model stable growth cycles arise due to monopolistic competition and complementarity between capital goods of different types.

\footnotetext{
${ }^{28}$ See Arifovic, Evans, and Kostyshyna (2020) for experimental evidence of coordination on stable inefficient steady states or sunspot fluctuations.
} 


\section{Concluding Remarks}

To be satisfactory as an equilibrium concept, rational expectations needs to be complemented by a stability analysis that shows how a rational expectations equilibrium can be attained. This essay has focused on using the adaptive learning approach, grounded in temporary equilibrium and bounded rationality, to assess stability and provide learning dynamics. We have seen that adaptive learning results have strong policy implications.

Moving forward there are many issues that need to be studied. Adaptive learning is becoming increasingly incorporated into empirical macroeconomics and financial economics models. A selection of examples include Milani (2007), Branch and Evans (2006b), Orphanides and Williams (2007), Milani (2011), Slobodyan and Wouters (2012), Eusepi and Preston (2011), Adam, Marcet, and Nicolini (2016), Chakraborty and Evans (2008) and Sinha (2016). In many cases the data reject restrictions imposed by RE but are consistent with adaptive learning. The implications of adaptive learning are also increasingly studied in laboratory experiments, e.g. Hommes (2011), Bao, Duffy, and Hommes (2013), Hommes and Lustenhouwer (2019), Arifovic, Evans, and Kostyshyna (2020) and Evans, Hommes, McGough, and Salle (2021).

In empirical and experimental applications there are significant choices to be made in how to model adaptive learning. Three broad unresolved issues are the decision horizon, how to specify forecast rules, and statistical learning vs. behavioral learning.

In Section 3 we briefly discussed the issue of the decision horizon. Longlived agents face difficult optimization problems, that depend on key aggregate variables far into the future. Should agents be assumed to use longhorizon or short-horizon decision rules?

Evans and McGough (2018c) show that in a stationary environment boundedly optimal short-horizon shadow-price learning can be asymptotically fully optimal under adaptive learning. On the other hand long-horizon decision-making appears particularly appropriate if there is anticipated structural change. Branch, Evans, and McGough (2013) show that both shorthorizon and infinite-horizon decision-making have intermediate finite-horizon counterparts. Empirically the decision horizon used by agents may be a key behavioral parameter, and this horizon length may depend on the economic situation agents face. Evans, Hommes, McGough, and Salle (2021) shows in a lab experiment that the forecast horizon can have a large effect on asset 
price dynamics.

If agents form expectations using statistical or econometric forecasting techniques, their models, just like econometric forecasting models used by economists, are likely subject to misspecification in terms of omitted variables or use of parsimonious lags. Model misspecification under adaptive learning can be readily addressed: the key equilibrium concept is a restricted perceptions equilibrium (RPE). In an RPE orthogonality conditions, that forecast errors be uncorrelated with regressors, must be satisfied. RPEs can be viewed as a bounded-rationality extension of an REE, and analogous Estability conditions can be obtained for RPEs.

An important empirical question therefore is the appropriate way to specify the forecast equations used by agents to form expectations. The answer may, of course, depend on whether we are considering households, firms, professional forecasters or central bank policymakers. It is also possible to allow for heterogeneity across agents in forecast rules, and to model agents as switching between forecast specifications based on recent performance, as in Branch (2004), Hommes (2011), Branch and Evans (2007) or Cho and Kasa (2015). One can also allow for the impact of the judgemental adjustments often used by professional forecasters or policymakers, as in Bullard, Evans, and Honkapohja (2008).

The specification issue leads in turn to the question of whether simple behavioral rules, of the type emphasized by Hommes (2011), or statistical forecast rules based on least-squares learning, provide a better description for how agents form expectations. The answer may well depend on whether the setting is a laboratory experiment, an empirical macro model, or survey data for households, firms or professional economists.

A criticism often made of bounded rationality models of expectations and decision-making is that, because of the wide range of ways to specify bounded rationality, it will be almost impossible to distinguish between them. However, each specification imposes strong restrictions on the data. The assumption that the economy is in an REE imposes tight cross-equation restrictions on the data. But analogous cross-equation restrictions also must be satisfied in a restricted perceptions equilibrium. Likewise constant-gain learning leads to specific forms of non-REE dynamics. Each behavioral model also has implications that are falsifiable. In addition, econometric tools are being developed for estimating models with adaptive learning. See Chritopeit and Massmann (2018). In some cases structural parameters not econometrically identified under RE are identified under adaptive learning. 
It is useful to conclude with one obvious policy implication of the alternative ways to model bounded rationality in macroeconomic settings. Especially when combined with uncertainty about values of key structural parameters of the macroeconomy, the range of ways to model boundedly rational decision-making indicates the need for policies that are robust to different implementations and alternative values of structural parameters. Examples of this approach in the adaptive learning literature are Orphanides and Williams (2007) and Evans and McGough (2007).

\section{References}

Adam, K., A. Marcet, and J. P. Nicolini (2016): "Stock Market Volatility and Learning," Journal of Finance, 71, 33-82.

Arifovic, J., G. W. Evans, and O. Kostyshyna (2020): “Are Sunspots Learnable? An Experimental Investigation in a Simple Macroeconomic Model," Journal of Economic Dynamics and Control, 110, 103775. https://doi.org/10.1016/j.jedc.2019.103775.

Azariadis, C. (1981): "Self-Fulfilling Prophecies," Journal of Economic Theory, 25, 380-396.

Azariadis, C., and R. Guesnerie (1982): "Propheties Creatrices et Persistence des Theories," Revue Economique, 33, 787-806.

(1986): "Sunspots and Cycles," Review of Economic Studies, 53, $725-737$.

Bao, T., J. Duffy, and C. Hommes (2013): "Learning, Forecasting and Optimizing: an Experimental Study," European Economic Review, 61, 186-204.

Benhabib, J., G. W. Evans, and S. Honkapohja (2014): "Liquidity Traps and Expectation Dynamics: Fiscal Stimulus or Fiscal Austerity?," Journal of Economic Dynamics and Control, 45, 220-238.

Benhabib, J., S. Schmitt-Grohe, and M. Uribe (2001): "The Perils of Taylor Rules," Journal of Economic Theory, 96, 40-69. 
Branch, W. A. (2004): "The Theory of Rationally Heterogeneous Expectations: Evidence from Survey Data on Inflation Expectations," Economic Journal, 114, 592-621.

Branch, W. A., and G. W. Evans (2006a): "Intrinsic Heterogeneity in Expectation Formation," Journal of Economic Theory, 127, 264-295.

(2006b): "A Simple Recursive Forecasting Model," Economic Letters, 91, 158-166.

Economic Dynamics, 10, 207-237.

(2011): "Learning about Risk and Return: A Simple Model of Bubbles and Crashes," American Economic Journal: Macroeconomics, 3, 159-191.

- (2017): "Unstable Inflation Targets," Journal of Money, Credit and Banking, 49, 785-806.

Branch, W. A., G. W. Evans, and B. McGough (2013): "Finite Horizon Learning," in Sargent and Vilmunen (2013), chap. 9.

Bullard, J., And S. Eusepi (2014): "When Does Determinacy Imply Expectational Stability?," International Economic Review, 55, 1-22.

Bullard, J., G. W. Evans, and S. Honkapohja (2008): "Monetary Policy, Judgment and Near-Rational Exuberance," American Economic Review, 98, 1163-1177.

Bullard, J., And K. Mitra (2002): "Learning About Monetary Policy Rules," Journal of Monetary Economics, 49, 1105-1129.

Cass, D., and K. Shell (1983): "Do Sunspots Matter?," Journal of Political Economy, 91, 193-227.

Chakraborty, A., and G. W. Evans (2008): "Can Perpetual Learning Explain the Forward Premium Puzzle?," Journal of Monetary Economics, $55,477-490$.

Cho, I.-K., And K. Kasa (2015): "Learning and Model Validation," Review of Economic Studies, 82, 45-82. 
Cho, I.-K., N. Williams, and T. J. Sargent (2002): "Escaping Nash Inflation," Review of Economic Studies, 69, 1-40.

Chritopeit, N., and M. Massmann (2018): "Estimating Structural Parameters in Regression Models with Adaptive Learning," Econometric Theory, 34, 68-111.

Clarida, R., J. Gali, and M. Gertler (1999): "The Science of Monetary Policy: A New Keynesian Perspective," Journal of Economic Literature, 37, 1661-1707.

Cochrane, J. H. (2011): "Determinacy and Identification with Taylor Rules," Journal of Political Economy, 119, 565-615.

- (2016): "Do Higher Interest Rates Raise or Lower Inflation?," Working paper, Hoover Institution and NBER.

Dixon, H., And N. Rankin (eds.) (1995): The New Macroeconomics: Imperfect Markets and Policy Effectiveness. Cambridge University Press, Cambridge UK.

Eusepi, S., And B. Preston (2010): "Central Bank Communication and Expectations Stabilization," American Economic Journal: Macroeconomics, 2, 235-271.

American Economic Review, 101, 2844-2872.

- (2018): "The Science of Monetary Policy: An Imperfect Knowledge Perspective," Journal of Economic Literature, 56, 3-59.

Evans, G. W. (1985): "Expectational Stability and the Multiple Equilibria Problem in Linear Rational Expectations Models," The Quarterly Journal of Economics, 100, 1217-1233.

(1989): "The Fragility of Sunspots and Bubbles," Journal of Monetary Economics, 23, 297-317.

Evans, G. W., And R. Guesnerie (1993): "Rationalizability, Strong Rationality, and Expectational Stability," Games and Economic Behaviour, 5, 632-646. 
Evans, G. W., R. Guesnerie, and B. McGough (2019): "Eductive Stability in Real Business Cycle Models," Economic Journal, 129, 821852.

Evans, G. W., E. Guse, and S. Honkapohja (2008): "Liquidity Traps, Learning and Stagnation," European Economic Review, 52, 1438-1463.

Evans, G. W., C. Hommes, B. McGough, and I. Salle (2021): "Are Long-horizon Expectations (De-)Stabilizing? Theory and Experiments," mimeo., University of Oregon.

Evans, G. W., and S. Honkapohja (1993a): "Adaptive Forecasts, Hysteresis and Endogenous Fluctuations," Federal Reserve Bank of San Francisco Economic Review, 1993(1), 3-13.

(1993b): "Learning and Economic Fluctuations: Using Fiscal Policy to Steer Expectations," European Economic Review, 37, 595-602.

(1994a): "Learning, Convergence, and Stability with Multiple Rational Expectations Equilibria," European Economic Review, 38, 1071-1098.

- (1994b): "On the Local Stability of Sunspot Equilibria under Adaptive Learning Rules," Journal of Economic Theory, 64, 142-161.

_ (1995): "Local Convergence of Recursive Learning to Steady States and Cycles in Stochastic Nonlinear Models," Econometrica, 63, 195-206.

(1998): "Economic Dynamics with Learning: New Stability Results," Review of Economic Studies, 65, 23-44.

(1999): "Learning Dynamics," in Taylor and Woodford (1999), chap. 7, pp. 449-542.

- (2001): Learning and Expectations in Macroeconomics. Princeton University Press, Princeton, New Jersey.

- (2003a): "Adaptive Learning and Monetary Policy Design," Journal of Money, Credit and Banking, 35, 1045-1072.

(2003b): "Expectations and the Stability Problem for Optimal Monetary Policies," Review of Economic Studies, 70, 807-824. 
(2006): "Monetary Policy, Expectations and Commitment," Scandinavian Journal of Economics, 108, 15-38.

_ (2007): "The E-Correspondence Principle," Economica, 74, 33-50.

- (2009): "Learning and Macroeconomics," Annual Review of Economics, 1, 421-451.

Evans, G. W., S. Honkapohja, and R. Marimon (2001): "Convergence in Monetary Inflation Models with Heterogeneous Learning Rules," Macroeconomic Dynamics, 5, 1-31.

(2007): "Stable Sunspot Equilibria in a Cash-in-Advance Economy," The B.E. Journal of Macroeconomics (Advances), pp. Iss. 1, Article 3.

Evans, G. W., S. Honkapohja, and K. Mitra (2016): "Expectations, Stagnation and Fiscal Policy," Discussion paper 11428, CEPR.

(2020): "Expectations, Stagnation and Fiscal Policy: a Nonlinear Analysis," Discussion paper 15171, CEPR.

Evans, G. W., S. Honkapohja, and P. Romer (1998): "Growth Cycles," American Economic Review, 88, 495-515.

Evans, G. W., And B. McGough (2005): "Monetary Policy, Indeterminacy and Learning," Journal of Economic Dynamics and Control, 29, 1809-1840.

- (2007): "Optimal Constrained Interest-Rate Rules," Journal of Money, Credit and Banking, 39, 1335-1356.

- (2018a): "Equilibrium Selection, Observability and BackwardStable Solutions," Journal of Monetary Economics, 98, 1-10.

(2018b): "Interest-Rate Pegs in New Keynesian Models," Journal of Money, Credit and Banking, 50, 939-965.

(2018c): "Learning to Optimize," mimeo, University of Oregon.

Oxford Research Encyclopedia of Economics and Finance,
https://doi.org/10.1093/acrefore/9780190625979.013.508.


(2020b): "Stable Near-rational Sunspot Equilibria," Journal of Economic Theory, 186, 104987. https://doi.org/10.1016/j.jet.2019.104987.

- (2021): "Agent-level Adaptive Learning," $O x$ ford Research Encyclopedia of Economics and Finance, https://doi.org/10.1093/acrefore/9780190625979.013.620.

Evans, G. W., and G. Ramey (1995): "Expectation Calculation, Hyperinflation and Currency Collapse," in Dixon and Rankin (1995), chap. 15, pp. 307-336.

Guesnerie, R. (1992): "An Exploration of the Eductive Justifications of the Rational-Expectations Hypothesis," American Economic Review, 82, $1254-1278$.

Econometrica, 70, 439-480.

- (2005): Assessing Rational Expectations 2: Eductive Stability in Economics. MIT Press, Cambridge, Mass.

Hicks, J. R. (1939): Value and Capital. Oxford University Press, Oxford UK.

Hommes, C. (2013): Behavioral Rationality and Heterogeneous Expectations in Complex Economics Systems. Cambridge University Press, Cambridge, UK.

Hommes, C. H. (2011): "The Heterogeneous Expectations Hypothesis: Some Evidence from the Lab," Journal of Economic Dynamics and Control, 35, 1-24.

Hommes, C. H., and J. Lustenhouwer (2019): "Managing Unanchored, Heterogeneous Expectations and Liquidity Traps," Journal of Economic Dynamics and Control, 101, 1-16.

Honkapohja, S., and K. Mitra (2004): "Are Non-Fundamental Equilibria Learnable in Models of Monetary Policy?," Journal of Monetary Economics, 51, 1743-1770. 
Honkapohja, S., K. Mitra, and G. W. Evans (2013): "Notes on Agents' Behavioral Rules Under Adaptive Learning and Studies of Monetary Policy," in Sargent and Vilmunen (2013), chap. 5.

HowitT, P. (1992): "Interest Rate Control and Nonconvergence to Rational Expectations," Journal of Political Economy, 100, 776-800.

Howitt, P., And R. P. McAfee (1992): "Animal Spirits," American Economic Review, 82, 493-507.

KASA, K. (2004): "Learning, Large Deviations, and Recurrent Currency Crises," International Economic Review, 45, 141-173.

Kocherlakota, N. (2016): "Neo-Fisherianism: A hopefully helpful analogy," Kocherlakota Thoughts on Policy blog post July 10, 2016.

Marcet, A., and J. P. Nicolini (2003): "Recurrent Hyperinflations and Learning," American Economic Review, 93, 1476-1498.

Marcet, A., and T. J. Sargent (1989): "Convergence of Least-Squares Learning Mechanisms in Self-Referential Linear Stochastic Models," Journal of Economic Theory, 48, 337-368.

McCallum, B. T. (2007): "E-stability vis-a-vis Determinacy Results for a Broad Class of Linear Rational Expectations Models," Journal of Economic Dynamics and Control, 31, 1376-1391.

McGough, B. (2006): "Shocking Escapes," Economic Journal, 116, 507528.

Milani, F. (2007): "Expectations, Learning and Macroeconomic Persistence," Journal of Monetary Economics, 54, 2065-2082.

- (2011): "Expectation Shocks and Learning as Drivers of the Business Cycle," Economic Journal, 121, 379-401.

Muth, J. F. (1961): "Rational Expectations and the Theory of Price Movements," Econometrica, 29, 315-335.

NAGEL, R. (1995): "Unraveling in Guessing Games: An Experimental Study," American Economic Review, 85, 1313-1326. 
Orphanides, A., and J. C. Williams (2007): "Robust Monetary Policy with Imperfect Knowledge," Journal of Monetary Economics, 54, 14061435 .

Preston, B. (2005): "Learning about Monetary Policy Rules when LongHorizon Expectations Matter," International Journal of Central Banking, $1,81-126$.

Razin, A., And E. SAdkA (eds.) (1987): Economic Policy in Theory and Practice. Macmillan, London.

Sargent, T. J. (1999): The Conquest of American Inflation. Princeton University Press, Princeton NJ.

(2008): "Evolution and Intelligent Design," American Economic Review, 98, 5-37.

Sargent, T. J., and J. Vilmunen (eds.) (2013): Macroeconomics at the Service of Public Policy. Oxford University Press.

Sargent, T. J., And N. Wallace (1987): "Inflation and the Government Budget Constraint," in Razin and Sadka (1987).

Shell, K. (1977): "Monnaie et Allocation Intertemporelle," Working paper, CNRS Seminaire de E.Malinvaud, Paris.

Sinha, A. (2016): "Learning and the Yield Curve," Journal of Money, Credit and Banking, 48, 513-547.

Slobodyan, S., and R. Wouters (2012): "Estimating a Medium-Scale DSGE Model with Expectations Based on Small Forecasting Models," American Economic Journal: Macroeconomics, 4, 65-101.

Taylor, J., And M. Woodford (eds.) (1999): Handbook of Macroeconomics, Volume 1. Elsevier, Amsterdam.

Williamson, S. (2016a): "More Neo-Fisher," New Monetarist Economics blog post July 18, 2016.

(2016b): "Neo-Fisherism: A Radical Idea, or the Most Obvious Solution to the Low-inflation Problem?," Regional Economist, Federal Reserve Bank of St. Louis, July 2016. 
Woodford, M. (1990): "Learning to Believe in Sunspots," Econometrica, 58, 277-307.

- (1999): "Optimal Monetary Policy Inertia," The Manchester School, Supplement, 67, 1-35.

- (2013): "Macroeconomic Analysis without the Rational Expectations Hypothesis," Annual Review of Economics, 5, 303-346. 